\title{
Resposta hemogasométrica de caprinos após transfusão homóloga de sangue total fresco ou armazenado
}

Nayanna Brunna da Silva Fonseca*, Jerson Marques Cavalcante, Jucélio da Silva Gameleira, Isabella Oliveira Barros, Estela Ivone Borges Lemos, Aluisio de Souza Neto, Talyta Lins Nunes, Rejane Santos Sousa, Antonio Humberto Hamad Minervino, Raimundo Alves Barrêto Júnior

Universidade Federal Rural do Semi-Árido (UFERSA), Mossoró, RN, Brasil

*Autor correspondente

e-mail: nayanna_brunna@yahoo.com.br

\section{Resumo}

A transfusão sanguínea é uma importante medida terapêutica para medicina veterinária, entretanto, não há estudos mostrando os efeitos da hemoterapia sobre o equilíbrio acidobásico de caprinos transfundidos. Desta forma, este trabalho teve como objetivo avaliar a resposta hemogasométrica de caprinos submetidos à transfusão homóloga de sangue total fresco ou armazenado por 15 e 35 dias. Foram utilizados 18 caprinos adultos, machos, submetidos a uma única flebotomia para retirada de $30 \%$ do volume sanguíneo e transfundidos com $20 \mathrm{~mL} / \mathrm{Kg}$ de sangue total armazenado em bolsas CPDA-1 de acordo com o grupo experimental, sendo: G0, composto por animais que receberam sangue fresco; G15 e G35, animais que receberam sangue armazenado em bolsas CPDA-1 por 15 e 35 dias, respectivamente. Amostras de sangue total venoso foram coletadas em seringas heparinizadas e analisadas em hemogasômetro portátil (i-STAT ${ }^{\circledR} 1$, Abbott Point of Care Inc, Illinois, EUA) com o uso de cartuchos i-STAT ${ }^{\circledR}$ CG8+ (Abbott Laboratories, Illinois, EUA) nos seguintes momentos: antes da indução da anemia (TC0); 6 horas após a flebotomia e antes de transfusão (TC1); 1, 6, 12, 24 e 96 horas após a transfusão (T1, T6, T12, T24 e T96, respectivamente). A avaliação hemogasométrica foi baseada na análise do potencial hidrogeniônico $(\mathrm{pH})$, pressão parcial de oxigênio $\left(\mathrm{PO}_{2}\right)$, pressão parcial de dióxido de carbono $\left(\mathrm{PCO}_{2}\right)$, saturação de oxigênio $\left(\mathrm{SO}_{2}\right)$, bicarbonato $\left(\mathrm{HCO}_{3}{ }^{-}\right)$, excesso de base (BE) e concentração total de dióxido de carbono $\left(\mathrm{TCO}_{2}\right)$. Cada determinação foi corrigida pela temperatura retal do animal correspondente. Amostras de sangue também foram retiradas das bolsas, antes da transfusão, para realização das mesmas análises. As análises estatísticas foram realizadas no programa estatístico GRAPHPAD PRISM 5.0, adotando-se nível de significância de 5\%. As bolsas de sangue armazenadas por 15 e 35 dias apresentaram mais alterações hemogasométricas do que as bolsas de sangue fresco. Não houve diferença entre grupos e entre os tempos estudados para o $\mathrm{BE}, \mathrm{HCO}_{3}$ - e $\mathrm{TCO}_{2}$. Com relação ao pH sanguíneo houve diferença entre grupos nos momentos TC1 e T96, onde o G15 apresentou 
menor pH. Na comparação entre tempos, observou-se aumento no pH no T1 do G15 quando comparado ao TC0. Quanto ao $\mathrm{PCO}_{2}$, o G0 apresentou maior $\mathrm{PCO}_{2}$ no T1 e o G15 apresentou maior $\mathrm{PCO}_{2}$ no T96. A PO foi maior no T6 do G0 e G15. Na comparação entre tempos, após a indução da anemia e transfusão sanguínea, observou-se redução na $\mathrm{PO}_{2}$ e $\mathrm{SO}_{2}$ no T96 do G0 e G15. Apesar dessas alterações, após a transfusão, os animais não apresentaram distúrbio acidobásico, pois todos os parâmetros ficaram dentro dos valores de referência para a espécie. Sendo assim, pode-se concluir que a transfusão de sangue homólogo total fresco ou armazenado em caprinos não comprometeu a gasometria dos animais transfundidos. 